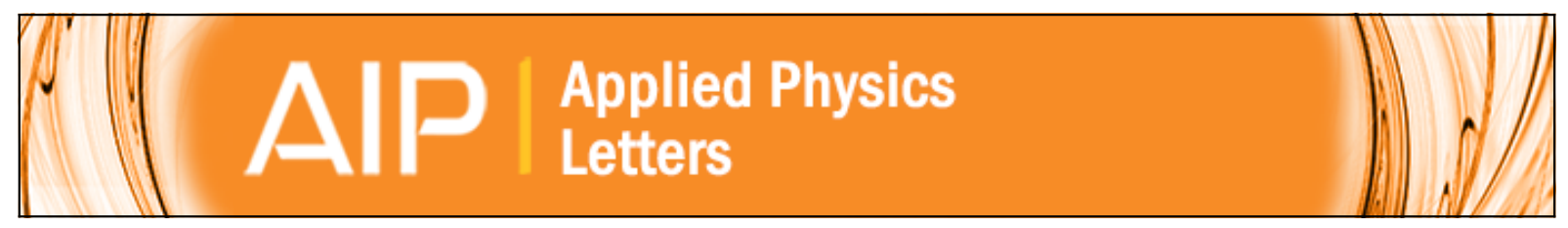

Recovery of remanent polarization of poly(vinylidene fluoride-co-trifluoroethylene) thin film after high temperature annealing using topographically nanostructured aluminium bottom electrode

Youn Jung Park, Seok Ju Kang, Cheolmin Park, Euntaek Woo, Kyusoon Shin, and Kap Jin Kim

Citation: Applied Physics Letters 90, 222903 (2007); doi: 10.1063/1.2743389

View online: http://dx.doi.org/10.1063/1.2743389

View Table of Contents: http://scitation.aip.org/content/aip/journal/apl/90/22?ver=pdfcov

Published by the AIP Publishing

Articles you may be interested in

High-temperature ferroelectric behaviors of poly(vinylidene fluoride-trifluoroethylene) copolymer ultrathin films with electroactive interlayers

J. Appl. Phys. 111, 064506 (2012); 10.1063/1.3699051

Nanoscale domain growth dynamics of ferroelectric poly(vinylidene fluoride- co -trifluoroethylene) thin films Appl. Phys. Lett. 96, 012908 (2010); 10.1063/1.3290247

Pyroelectric study of polarization switching in Langmuir-Blodgett films of poly(vinylidene fluoride trifluoroethylene) J. Appl. Phys. 98, 044107 (2005); 10.1063/1.2006228

Electrostrictive and dielectric properties of stretched poly(vinylidene fluoride-trifluoroethylene) copolymers at cryogenic temperatures

Appl. Phys. Lett. 83, 1821 (2003); 10.1063/1.1606101

Transverse strain responses in electrostrictive poly(vinylidene fluoride-trifluoroethylene) films and development of a dilatometer for the measurement

J. Appl. Phys. 86, 2208 (1999); 10.1063/1.371032

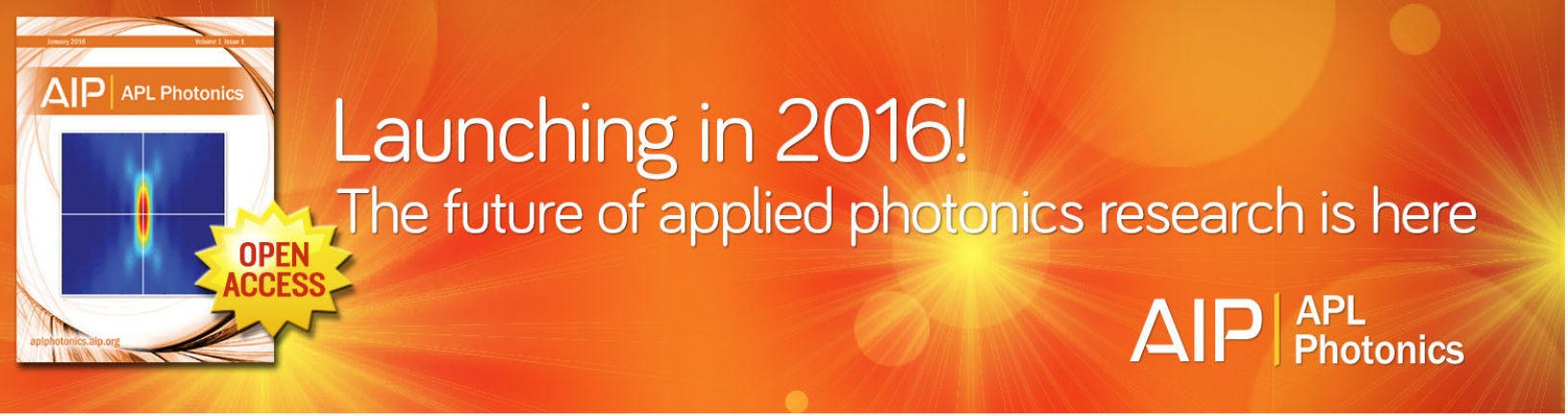




\title{
Recovery of remanent polarization of poly(vinylidene fluoride-co-trifluoroethylene) thin film after high temperature annealing using topographically nanostructured aluminium bottom electrode
}

\author{
Youn Jung Park, Seok Ju Kang, and Cheolmin Park ${ }^{a)}$ \\ Department of Materials Science and Engineering, Yonsei University, Seoul 120-749, Korea \\ Euntaek Woo and Kyusoon Shin \\ School of Chemical and Biochemical Engineering, Seoul National University, Seoul 151-744, Korea \\ Kap Jin Kim \\ College of Environment and Applied Chemistry, Kyung Hee University, Gyeonggi-do 446-701, Korea
}

(Received 29 January 2007; accepted 2 May 2007; published online 30 May 2007)

\begin{abstract}
Facile recovery of ferroelectric polarization after high temperature annealing was observed in a poly(vinylidene fluoride-co-trifluoroethylene) (P(VDF-TrFE)) thin film on an etched Al bottom electrode which has a topographically nanostructured surface with hexagonal registry of the recessed hemispherical bowls of approximately $100 \mathrm{~nm}$ diameter. Fairly large remanent polarization of $10 \mu \mathrm{C} / \mathrm{cm}^{2}$ was obtained after annealing up to $185^{\circ} \mathrm{C}$ with the etched $\mathrm{Al}$ electrode, while the polarization rapidly dropped near the melting temperature of $\mathrm{P}(\mathrm{VDF}-\mathrm{TrFE})\left(\sim 150{ }^{\circ} \mathrm{C}\right)$ with a flat $\mathrm{Al}$ electrode. The topographic electrode is found to facilitate the reorganization of $\mathrm{P}(\mathrm{VDF}-\mathrm{TrFE})$ crystal under electric field. (C) 2007 American Institute of Physics. [DOI: 10.1063/1.2743389]
\end{abstract}

Polymer ferroelectricity originating from the bistability of permanent electrical dipoles across the long macromolecular backbone is one of the attractive properties in poly(vinylidene fluoride-co-trifluoroethylene) (P(VDF-TrFE)) for the nonvolatile memory applications. ${ }^{1-3}$ For low voltage operation of the polymer devices, it is necessary to fabricate as thin polymer films as possible with large crystallinity and effective crystal orientation maintained over broad temperature range. ${ }^{4-6}$ In our recent work, we have found that thermal annealing above the melting temperature $T_{m}\left(\sim 150{ }^{\circ} \mathrm{C}\right)$ of $\mathrm{P}(\mathrm{VDF}-\mathrm{TrFE})$ thin film gives rise to irreversible extinction of ferroelectric polarization due to the permanent polymer crystal rotation to its $b$ axis perpendicular to electric field, which suggests that the fabrication of $\mathrm{P}(\mathrm{VDF}-\mathrm{TrFE})$ capacitors is undesirable above $T_{m}$. It is, therefore, essential to find a way to provide sufficient thermal stability of ferroelectric properties above $T_{m}$ for the realization of polymer ferroelectric memory.

Many different types of chemical and topological interlayers including self-assembled monolayers, LiF thin layer, and anodized aluminium oxide (AAO) layers have been employed for the improved performance of various organic electronic devices such as transistors and light emitting diodes and so on. ${ }^{7,8}$

We envision in this work that the topographic and periodic self-assembled nanotexture of an etched Al substrate, incorporated as a bottom electrode into a ferroelectric $\mathrm{P}(\mathrm{VDF}-\mathrm{TrFE})$ based capacitor, can influence the formation and ordering of ferroelectric crystalline domains so that the performance of the capacitor is enhanced.

A schematic of the capacitor is shown in Fig. 1(a). Polymer films were sandwiched between two different electrodes. The bottom electrode was prepared by anodization of pure $\mathrm{Al}$ (99.999\%, Goodfellow Cambrige Limited) in $0.3 M$ oxalic

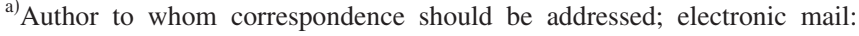
cmpark@yonsei.ac.kr
}

acid and following chemical etching in chromic acid mixture. ${ }^{9}$ An etched Al electrode has the recessed hemispherical bowls hexagonally packed with uniform diameter of approximately $100 \mathrm{~nm}$ on the surface of itself, as demonstrated in atomic force microscope (AFM) image in Fig. 1(b). We employed a P(VDF-TrFE) with 27.5 wt $\%$ TrFE (MSI Sensor, PA). $T_{m}$ and Curie temperature $\left(T_{C}\right)$ of the bulk polymer are 150 and $80{ }^{\circ} \mathrm{C}$, respectively. ${ }^{4}$ Thin films were formed by spin coating with $1 \%-3 \%$ solution in methyl ethyl ketone. Thickness of the film was measured by ellipsometry (Gaertner Scientific Co.), ranging from approximately 70 to $200 \mathrm{~nm}$. P(VDF-TrFE) films were also prepared on a thermally grown flat $\mathrm{Al}$ substrate for comparison. Aluminum top electrodes were evaporated on polymer films using a shadow mask with holes of $200 \mu \mathrm{m}$ in diameter under pressure of $\sim 10^{-6}$ mbars and a rate of $0.1-0.2 \mathrm{~nm} / \mathrm{s}$. Ferroelectric properties were obtained using a virtual ground circuit (Radiant Technologies Precision LC unit). All measurements were done at room temperature. The structures of the films were characterized by scanning electron microscopy (SEM) (HITACHI S-2700) and the grazing-incidence x-ray diffraction (GIXD). (a)

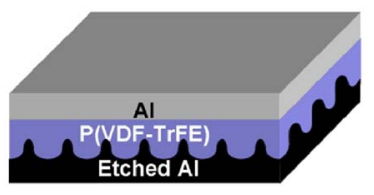

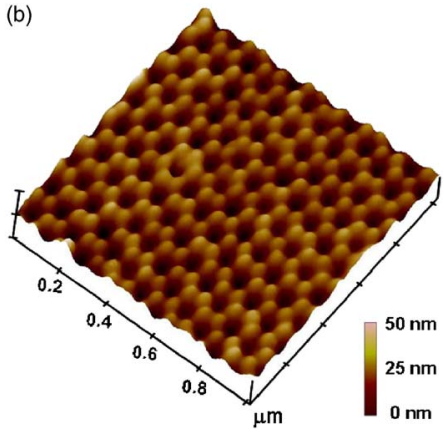

FIG. 1. (Color online) (a) Schematic of the ferroelectric P(VDF-TrFE) capacitor with the etched Al surface as a bottom electrode. (b) A tapping mode-AFM image of an etched Al bottom electrode. 

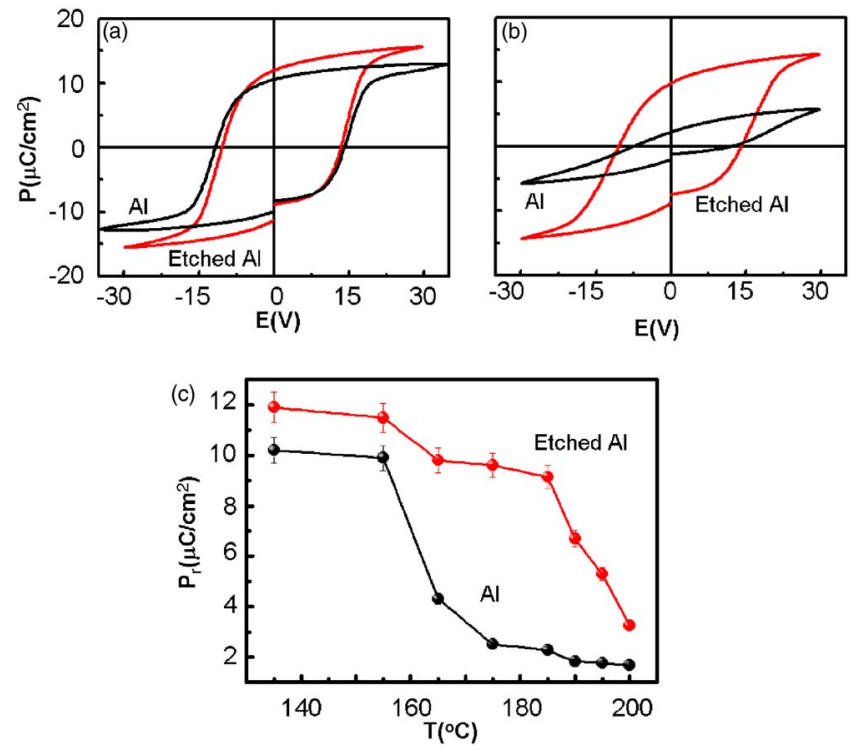

FIG. 2. (Color online) Polarization $P$ vs applied voltage $E$ hysteresis loops of P(VDF-TrFE) capacitors with $200 \mathrm{~nm}$ in thickness on two different surfaces: an etched $\mathrm{Al}$ and a flat $\mathrm{Al}$ electrode after annealed (a) at $135^{\circ} \mathrm{C}$ and (b) at $185^{\circ} \mathrm{C}$. (c) $P_{r}$ of $\mathrm{P}(\mathrm{VDF}-\mathrm{TrFE})$ thin films as a function of annealing temperature on an etched $\mathrm{Al}$ substrate (red) and a flat $\mathrm{Al}$ one (black). Each value of $P_{r}$ was taken from the $P-E$ loops when $\pm 30 \mathrm{~V}$ was applied.

First of all, we characterized the ferroelectric polarization hysteresis loops of $\mathrm{P}(\mathrm{VDF}-\mathrm{TrFE})$ fabricated on both types of bottom electrodes with and without topographic pattern after annealing at $135{ }^{\circ} \mathrm{C}$ for $2 \mathrm{~h}$. We obtained $P-E$ curves from 10 to $30 \mathrm{~V}$ with the step of $2 \mathrm{~V}$. As-cast samples with both substrates did not show saturated loops due to low crystallinity, as previously reported. ${ }^{4}$ Figure 2(a) shows well-saturated polarization curves from capacitor with two different electrodes after annealing. The improvement of the remanent polarization $\left(P_{r}\right)$ is attributed to the enhanced crystallinity during annealing between $T_{C}$ and $T_{m}$ with the preferred orientation of crystal with the $b$ axis parallel to electric field. ${ }^{4} P_{r}$ in a saturated curve with an etched $\mathrm{Al}$ and a flat electrode are approximately 12.2 and $10 \mu \mathrm{C} / \mathrm{cm}^{2}$, respectively, when the applied sweep voltage is above $\pm 30 \mathrm{~V}$. Coercive voltage for both cases is similar and approximately $10 \mathrm{~V}$. Slightly large value of $P_{r}$ in the device with the etched $\mathrm{Al}$ seems to be due to the increased contact area of polymer film with the electrode. ${ }^{10}$

To see the ferroelectric properties after melt and recrystallization, $\mathrm{P}(\mathrm{VDF}-\mathrm{TrFE})$ films previously annealed at $135^{\circ} \mathrm{C}$ for $2 \mathrm{~h}$ were further annealed from $155^{\circ} \mathrm{C}$, just above $T_{m}$, to $230^{\circ} \mathrm{C}$. Measurement of polarization was done at RT after the thermal treatment at each temperature for 30 min. A precipitous drop of $P_{r}$ was observed in the range from 155 to $160^{\circ} \mathrm{C}$, and it is possible to detect a small amount of polarization which further decreases with more elevated temperature annealing in the case of using a flat $\mathrm{Al}$ electrode, as shown in Fig. 2(c). As demonstrated in our previous work, ${ }^{4}$ the orientation of $\mathrm{P}(\mathrm{VDF}-\mathrm{TrFE})$ crystal is changed with its polar $b$ axis parallel to the substrate during recrystallization, resulting in the extinction of polarization in $\mathrm{P}(\mathrm{VDF}-\mathrm{TrFE})$ films on a flat $\mathrm{Al}$ electrode. In contrast, the annealing above $T_{m}$ with a capacitor with the etched Al bottom electrode gave rise to $P_{r}$ of $10 \mu \mathrm{C} / \mathrm{cm}^{2}$, approximately $10 \%$ drop of its highest polarization at $135^{\circ} \mathrm{C}$. Fairly large ferroelectric polarization in the capacitor was maintained
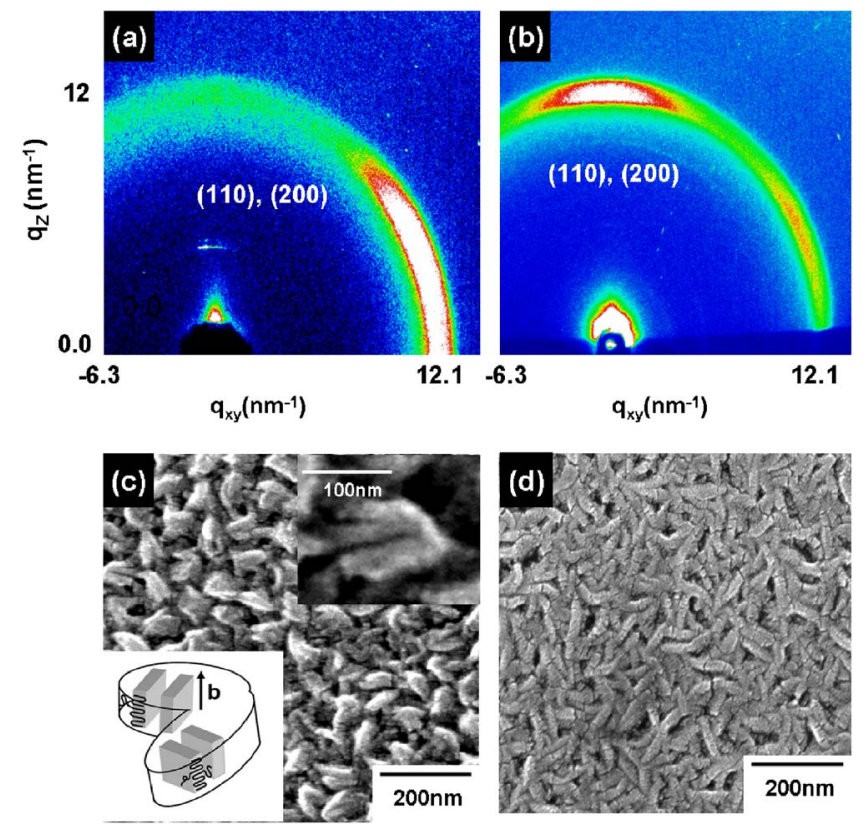

FIG. 3. (Color online) 2D GIXD patterns for P(VDF-TrFE) thin films on an etched $\mathrm{Al}$ electrode (a) after annealing at $185^{\circ} \mathrm{C}$ and (b) after electrical poling with $\pm 30 \mathrm{~V}$, following the annealing at $185^{\circ} \mathrm{C}$. The reflections are preferentially located near (a) equator and (b) meridian, respectively. SEM images of $\mathrm{P}(\mathrm{VDF}-\mathrm{TrFE})$ thin film annealed at $135^{\circ} \mathrm{C}$. (c) The polymer surface contacted with an etched Al substrate. (d) The top surface of the polymer film on a flat Al substrate. The insets of (c) display a SEM image and a schematic of needlelike P(VDF-TrFE) crystal severely bent to accommodate itself into the recessed hemispherical bowl.

even after annealing at $185{ }^{\circ} \mathrm{C}$ and suddenly decreased to about $3.5 \mu \mathrm{C} / \mathrm{cm}^{2}$ at $200{ }^{\circ} \mathrm{C}$, as shown in Fig. 2(c). It should be noted that the value at $200{ }^{\circ} \mathrm{C}$ with the etched $\mathrm{Al}$ is still higher than that with the flat Al. No effect of the cooling rate after annealing was found on the polarization of the film on an etched Al substrate. The difference of ferroelectric behavior between the capacitors with two electrodes is clearly shown in Fig. 2(b).

In order to understand the unusual recovery of ferroelectric polarization after high temperature annealing above $T_{m}$ with the etched Al bottom electrode, we performed grazing angle $\mathrm{x}$-ray scattering of thin $\mathrm{P}(\mathrm{VDF}-\mathrm{TrFE})$ films annealed at various temperatures. Similar to the samples on a flat $\mathrm{Al}, b$ axis of $\mathrm{P}(\mathrm{VDF}-\mathrm{TrFE})$ crystals was preferentially aligned perpendicular to etched $\mathrm{Al}$ in the samples annealed below $T_{m}$ (data not shown). In addition, the annealing above $T_{m}$ of a sample preheated at $135{ }^{\circ} \mathrm{C}$ for $2 \mathrm{~h}$ rotated the orientation of crystal $b$ axis into one parallel to etched $\mathrm{Al}$ substrate. For example, a two-dimensional (2D) x-ray pattern of the sample treated at $185^{\circ} \mathrm{C}$ shown in Fig. 3(a) clearly visualizes the (110) and (200) reflections intensified near equator, which indicates the preferential ordering of crystal $c$ axis perpendicular to the substrate. As mentioned previously, the orientation we achieved, very similar to that with flat $\mathrm{Al}$, is not effective to induce such $P_{r}$ observed in Fig. 2(b).

The difference between two samples with dissimilar bottom electrodes occurred when poled with relatively low sweeping electric field below $\pm 30 \mathrm{~V}(\sim 1.5 \mathrm{MV} / \mathrm{cm})$ at room temperature. There was no orientation change in the sample with a flat $\mathrm{Al}$ electrode under the electric field. In contrast, the intense (110) and (200) reflections near equator, observed in the sample with an etched $\mathrm{Al}$ electrode annealed at $185^{\circ} \mathrm{C}$ [Fig. 3(a)], were changed to ones near meridian upon appli- 
cation of the electric field [Fig. 3(b)]. It is noted that there is some residual reflection near equator, as shown in Fig. 3(b). The preferred orientation near meridian implies that the polar $b$ axis, responsible for polarization, is dominantly perpendicular to the etched Al substrate and consequently, now, effectively aligned along the electric field, giving rise to the saturated hysteresis with high $P_{r}$ observed in Fig. 2(b). A plausible reason of the polarization is due to the corrugated surface, on which the reorientation of $c$ axis parallel to the substrate leads to the occurrence of switchable components of the polarization vectors arising from the local curvature of the substrate, while negligible on flat one. Interestingly, a sample with an etched $\mathrm{Al}$ electrode annealed at $200{ }^{\circ} \mathrm{C}$ and treated with poling did not show any crystal reorganization, similar to one shown in Fig. 3(b), which is consistent with the behavior of the small polarization in Fig. 2(c) but hardly understandable with the reason mentioned above.

Recent work by Wang et al. has demonstrated that the crystalline lamellar orientation of an ultrathin melt-drawn PVDF film is still preserved after melting and recrystallization on carbon surface. ${ }^{11}$ In our system, the similar behavior may occur in very thin $\mathrm{P}(\mathrm{VDF}-\mathrm{TrFE})$ layer bound onto the topographic and periodic nanostructure of an etched $\mathrm{Al}$ upon melt and recrystallization. The ultrathin effective layer, which has the memory of the crystal orientation before melting near the etched $\mathrm{Al}$ electrode surface, is speculated to facilitate the reorganization of crystal to its $b$ axis perpendicular to the etched $\mathrm{Al}$ substrate under the low electric field, leading to the fairly large polarization. The capability of structural reorganization of $\mathrm{P}(\mathrm{VDF}-\mathrm{TrFE})$ at room temperature has been already confirmed under approximately $1 \mathrm{MV} / \mathrm{cm}$ in our previous work. ${ }^{12}$

The crystal memory effect that the orientation of a polymer crystal obtained by fabrication process below $T_{m}$ reappears even after melting, and recrystallization has been reported in many different semicrystalline polymers. ${ }^{11,13,14}$ When the experimental temperature for polymer crystal melting is not sufficiently high above its $T_{m}$, amorphous polymer chains stay near the place originally located in the crystalline lamellae due to the lack of chain mobility. The subsequent crystallization makes the chains form crystal lamellae with the orientation similar to one before melting. In our system, the annealing of $\mathrm{P}(\mathrm{VDF}-\mathrm{TrFE})$ thin film at $200{ }^{\circ} \mathrm{C}$ well above $T_{m}$ may completely randomize the previous chain conformation to lose the crystal memory, resulting in a very small polarization observed in Fig. 2(c).

It is, therefore, obvious that a prerequisite for the large polarization after annealing above $T_{m}$ is the formation of sufficient amount of $\mathrm{P}(\mathrm{VDF}-\mathrm{TrFE})$ crystals with the preferred orientation achieved by the annealing at $135{ }^{\circ} \mathrm{C}$. The detachment method using poly(acrylic acid) solution ${ }^{15}$ allowed us to examine the bottom surface of a P(VDF-TrFE) film annealed at $135^{\circ} \mathrm{C}$, which was directly contacted with an electrode. Figure 3(c) clearly visualizes the characteristic needlelike crystals with the width of approximately $30 \mathrm{~nm}$ effectively packed onto the recessed periodic Al surface. Compared with the typical needlelike crystals with the length and width of approximately 200 and $30 \mathrm{~nm}$, respectively, observed on a flat surface [Fig. 3(d)], the individual needlelike microdomain is severely bent to accommodate itself into each hemispherical patterned domain, as shown in the insets of Fig. 3(c). No ferroelectric polarization was observed in a sample directly annealed at $170{ }^{\circ} \mathrm{C}$ after spin casting without thermal treatment at $135{ }^{\circ} \mathrm{C}$.

An etched Al bottom electrode with topographic and periodic nanostructure was very effective to recover the ferroelectric polarization of $\mathrm{P}(\mathrm{VDF}-\mathrm{TrFE})$ thin film after thermal annealing up to $185^{\circ} \mathrm{C}, 35^{\circ} \mathrm{C}$ higher than $T_{m}$. The presence of an etched $\mathrm{Al}$ electrode allowed the crystal, oriented with its $b$ axis parallel to the electrode arising from the melt and recrystallization, ${ }^{6}$ to more easily reorganize into the orientation, in which crystal $b$ axis was perpendicular to the electrode, responsible for the large ferroelectric polarization.

This project was supported by The National Research Program for the 0.1 Terabit Non-Volatile Memory Development sponsored by Korea Commerce, Industry and Energy. Samsung Electronics, Co., Ltd. The X-ray experiments at PAL (4C2 beamline, Korea) were supported by MOST and POSCO, Korea. This work was supported by Seoul Science Foundation and the Second Stage of Brain Korea 21 Project in 2006.

${ }^{1}$ F. Xia, H. S. Xu, F. Fang, B. Razavi, Z.-Y. Cheng, Yu. Lu, B. Xu, and Q. M. Zhang, Appl. Phys. Lett. 78, 1122 (2001).

${ }^{2}$ R. C. G. Naber, C. Tanase, P. W. M. Blom, G. H. Gelinck, A. W. Marsman, F. J. Touwslager, S. Setayesh, and D. M. de Leeuw, Nat. Mater. 4, 243 (2005).

${ }^{3}$ G. H. Gelinck, A. W. Marsman, F. J. Touwslager, S. Setayesh, D. M. de Leeuw, R. C. G. Naber, and P. W. M. Blom, Appl. Phys. Lett. 87, 092903 (2005).

${ }^{4}$ Y. J. Park, S. J. Kang, K. J. Kim, H. S. Lee, M. S. Lee, U.-I. Chung, I. J. Park, and C. Park, Appl. Phys. Lett. 88, 242908 (2006).

${ }^{5}$ T. R. Dargaville, M. Celina, and P. M. Chaplya, J. Polym. Sci., Part B: Polym. Phys. 43, 1310 (2005).

${ }^{6}$ F. Xia, H. Y. K. Wang, H. Li, C. Huang, Y. Ma, Q. M. Zhang, Z.-Y. Cheng, and F. B. Bateman, J. Polym. Sci., Part B: Polym. Phys. 41, 797 (2003).

${ }^{7}$ B. D. Chin, L. Duan, M.-H. Kim, S. T. Lee, and H. K. Chung, Appl. Phys. Lett. 85, 4496 (2004).

${ }^{8}$ K. Shin, H. Xiang, S. I. Moon, T. Kim, T. J. McCarthy, and T. P. Russell, Science 306, 76 (2004).

${ }^{9}$ Y. M. Sun, M. Steinhart, D. Zschech, R. Adhikari, G. H. Michler, and U. Gosele, Macromol. Rapid Commun. 26, 369 (2005).

${ }^{10}$ K. W. Guarini, C. T. Black, Y. Zhang, H. Kim, E. M. Sikorski, and I. V. Babich, J. Vac. Sci. Technol. B 20, 2788 (2002).

${ }^{11}$ J. Wang, H. Li, J. Liu, Y. Duan, S. Jiang, and S. Yan, J. Am. Chem. Soc. 125, 1496 (2003).

${ }^{12}$ K. J. Kim and G. B. Kim, Polymer 38, 4881 (1997).

${ }^{13}$ B. Wunderlich, Macromolecular Physics (Academic, New York, 1976), Vol. 2, pp. 52-70.

${ }^{14}$ P. D. Olmsted, W. C. K. Poon, T. C. Mcleish, N. J. Terrill, and A. J. Ryan, Phys. Rev. Lett. 81, 373 (1998).

${ }^{15}$ C. Park, J. Y. Cheng, M. J. Fasolka, A. M. Mayes, C. A. Ross, and E. L. Thomas, Appl. Phys. Lett. 79, 848 (2001). 